\title{
From knowledge co-creation to value co-creation and beyond: challenging global emergency in smart service systems.
}

\author{
Francesco Polese \\ Department of Business Science, \\ Management and Innovation \\ Systems (DISA-MIS) \\ University of Salerno, Italy \\ fpolese@unisa.it
}

\author{
Orlando Troisi \\ Department of Business Science, \\ Management and Innovation \\ Systems (DISA-MIS) \\ University of Salerno, Italy \\ otroisi@unisa.it
}

\author{
Mara Grimaldi \\ Department of Business Science, \\ Management and Innovation \\ Systems (DISA-MIS) \\ University of Salerno, Italy \\ margrimaldi@unisa.it
}

\begin{abstract}
The study seeks to investigate the impact of pandemic on teaching and learning processes involved in Higher Education (HE) by analysing the way in which knowledge exchange and value co-creation are reframed through ICTs and technology.

The adoption of the interpretative lens of Service Science permits to reread HE as a smart service system. The empirical research, based on content analysis as an inquiry, analyses: 1) the transformations introduced in technology adoption, information sharing, knowledge and value co-creation to comply with the disruption "imposed" by i the sanitary emergency; 2) the way in which this transformation can introduce novelties in Higher education system. The results identify the different drivers for value and knowledge co-creation that can be implemented in technology-enhanced teaching and learning and the different novelties that can be generated from the emergence of innovation.
\end{abstract}

\section{Introduction}

Covid-19 forces companies and organizations all around the world to comply with a complex set of technological, political, social, and managerial evolutions, which are changing dramatically business management, people's interactions, daily lives, and work environment (Kabadayi et al., 2020; Heinonen and Strandvik, 2020). The challenge to the global pandemic requires companies to reorient their strategies, redesign their business models and redefine their relationships with stakeholders.

This redefinition seems to have effects both on human's interactions and on their use of technologies by introducing new waves of innovation (Azoulay and Jones, 2020) in different industries and business contexts and by advancing new tools, platforms, applications and means to manage old problems (relational asymmetry, information sharing, knowledge management).

To analyze how the technological challenges posed by pandemic can redefine human-computer interactions, organizations should be re-conceptualized as smart service systems, (Lim et al., 2016; Lim and Maglio, 2019) to take into account how the increased connectivity and the technological "forced" evolution of Covid-era era can improve information sharing, data analysis and knowledge exchange analyze by improving innovation opportunities (Spohrer and Demirkan, 2015; Polese et al., 2020a). Through the lens of service science, organizations can be explored as complex systems in which the active engagement of people, through human-computer interactions and information sharing with organizations, can lead to the codevelopment of innovative solutions for the well-being of all the stakeholders in the system.

Based on the recognized relationship between value co-creation (VCC) and innovation (Lusch and Nambisan, 2015; Storbacka et al., 2016; Helkkula et al., 2018), this work aims at rereading contemporary companies that seek to manage epidemic as smart service systems, grounded on technology-enabled interactions that allow the constant exchange of skills and the sharing of risks, resources and responsibilities to pursue jointly common value propositions (Romero and Molina 2009).

Despite the relevant role of technology on the emergence of innovation, previous studies on service innovation gradually shift towards the attention from the study of the "simple" technological innovation to the adoption of a systems orientation (Vargo et al., 2015) which identifies the need to integrate the technological dimension with the human side of innovation. Therefore, it can be noticed that the use of technology per se does not imply the automatic achievement of innovation: only through the application of human skills and knowledge new entities can be co-created. 
In smart service systems, the actors that encourage actively the generation of innovation are defined lead users and their key contribution is the sharing of knowledge: this process can be defined as knowledge co-creation (KCC, Prahalad and Ramaswamy, 2003; Hsieh and Chen 2005; Von Hippel 2005). Knowledge co-creation involves the analysis, sharing, assimilation and creation of knowledge (Su et al., 2016) obtained from the contribution of unique resources and valuable skills from a series of actors during value co-creation. Through the integration of different capabilities and competences, each stakeholder can provide the right cognitive variety to stimulate the generation of new knowledge, develop new ideas for organizational change, improve extant services or the create new ones. Different types of stakeholders, in various exchange contexts and in different economic and social conditions can release multiple resources, by giving rise to various innovative practices.

Due to the interconnection between knowledge cocreation (KCC), value co-creation (VCC) and the emergence of co-developed innovation (co-innovation) in current smart service systems, the aim of the study is to reveal, on the one hand, the key enabling dimensions for knowledge co-creation an value co-creation in contemporary organizations engaged in the fight against Covid-19, and to explore, on the other hand, how these can be dynamically combined through multi-leveled relationships between human-computer interactions and knowledge integration processes to give life to new technologies, business processes, strategies, value.

Therefore, the study seeks to answer the following research questions:

RQ1- Which are the enabling dimensions that activate the co-creation of knowledge (KCC) and new value (VCC) in smart service systems to manage the pandemic?

RQ2- How can the-created new values and knowledge lead to the co-development of innovation?

Knowledge co-creation, value co-creation and the co-development of new value and practices are dynamic processes arising from the combination of multilevelled transformations at individual, relational and collective levels of exchange (Polese et al., 2020b) that can determine social change (Visvizi et al., 2018) in the long run. To challenge the pandemic, smart service systems should address a paradox by managing continuity, firstly, and by transforming and innovating interactions, relational modalities and co-creation practices, secondly.

The article aims at advancing the debate on two key issues: 1) how the new technological tools and the new human-computer interactions required to comply with the new scenario and with the requirements posed by the pandemic can improve knowledge and value sharing and co-creation (RQ1); 2) how smart service systems can manage the emergence of innovation and become catalysts for social change (RQ2) to shape and renew the rules, interactions and culture of the communities with which actors are engaged.

Starting from the IAU (International Association of Universities) Global Reports, that provides a first global overview of the disruption caused by COVID-19 on higher education, the study analyses some cases from the education context through the lens of Service Science to identify the different technological touchpoints that can be implemented in teaching and learning processes to boost co-creation of knowledge and value and identify the different mechanisms that can foster the emergence of innovation.

The identification of the enablers of innovation and societal changes and of the new interaction modalities and main strategies to challenge the pandemic can help scholars and practitioners identify the key drivers to overcome social and economic crisis. Moreover, the elaboration of a framework that analyses how technology can redefine human-computer interactions to enable value co-creation and innovation can advance the conceptualization of systems innovation to go beyond the technological focus on innovation revealed in extant research.

\section{Theoretical background}

To address the key role of technologies in the redefinition of contemporary markets, the most recent theories on services should be considered as the most appropriate theoretical foundations that can help redefine organizations as complex service systems which, through the interactions between actors, enhanced by smart technologies and ICTs (information and communication technologies), can co-create value (Davis et al., 2011; Troisi et al., 2021).

By proposing the concept of smart service system (Barile and Polese, 2010; Lim et al., 2016), Service Science explores the impact of information flows, enhanced through digitization, on the co-creation of value and knowledge to identify the factors that enable systematic innovation.

For this reason, the section defines, firstly, the key elements of smart service systems and, secondly, the processes of value co-creation (paragraph 2.1) and knowledge co-creation (paragraph 2.2) that could be generated multi-levelled organizations.

\subsection{Smart service systems and the role of technology}


Service Science (Spohrer et al., 2007; Maglio and Spohrer, 2008; Maglio et al., 2019) defines organizations as service systems, or "configurations of value co-creation deriving from a set of people, technologies, value propositions, which interact with other service systems internally and externally through shared information" (Spohrer et al., 2008, p. 5).

With the advent of digitalization, service systems are reframed as smart service systems (Barile and Polese, 2010; Lim et al., 2016) in which the tools offered by new technologies provide new ways to increase the cocreation of value and, therefore, innovation (Edvardsson et al., 2014).

The main dimensions of service systems (organizations, people, technology, shared information) can be redefined through the application of smart technologies that improve automation and connectivity, by enhancing interactions and information exchanges between actors (Lim et al., 2016). Smart service systems create value through the synergy deriving from some relevant enabling dimensions, the so-called "4Cs" (Lim and Maglio, 2019): 1) connection; 2) data collection; 3) communication; 4) computation.

The transition from service systems to smart service systems can be understood as the result of the "urgent" need to move to a data-based approach to the study of the emergence of value co-creation processes. Therefore, reformulating service systems through the lens of smartness helps to understand the implications of ICTs on organizations, on the ways of sharing information and of technologies, which enables, facilitates, intensifies exchanges or give life to new relational modalities.

The dynamic and unrepeatable synergy among the 4 Cs can give rise to the co-creation of value and the systematic creation of innovation (Carrubbo et al., 2015), by creating in the systems a continuous state of change and innovative tension based on the search for the proactive co-evolution of organizations to challenge environmental dynamism. The information exchanged which originates from a continuous collection of raw "data" and of potentially relevant information - is interpreted and "aimed" at learning, by increasing the effectiveness of decisions and improving the service $(\mathrm{Ng}, 2015)$.

The main elements of service systems (people, organization, technology, shared information) can be redefined through smart technologies, that enhance the automation and connectivity in the system, by improving interactions and exchanges of information between people and organizations (Lim et al., 2016). As depicted in Figure 1, organizations-people interactions are boosted by the exponential increase of contact points and technological channels ("smart" dimension 1: connection). Secondly, the information exchanged is more immediate and transparent ("smart" dimension 2: communication) through technologies that are mostly focused on data collection and analysis ("smart" dimension 3: data collection) using the application of analytics ("smart" dimension 4: computation) aimed at extracting relevant information from the data that favours the co-creation of value, by helping the system adapt to environmental changes and overcome crisis by adopting flexible models. ICT-enhanced tools and solutions enable the continuous collection of data, which if managed appropriately (Lytras et al., 2021), allows at obtaining new value from the data collected. The concept of smart service systems (Barile \& Polese, 2010; Lim \& Maglio, 2016, Spohrer et al., 2007; Maglio \& Spohrer, 2008) permits to explore the active engagement of people, who through human-computer interactions with organizations can co-create value and innovative solutions. In this way, the adoption of Service science can contribute to conceptualize the capability of contemporary systems organization to react to environmental turbulences by transforming the crisis into an opportunity for innovation through technology and information sharing, which helps interpreting and overcoming the unpredictable phenomena by reducing chaos and fostering the enrichment of new knowledge.

\subsection{From value co-creation to knowledge co- creation: the pursuit of innovation to challenge emergency}

Service science and the conceptualization of smart service systems permit to analyze organizations as complex configurations of actors that integrate resources, communicate, share information and compute data to co-create value and new knowledge. Thus, this perspective can offer the right interpretative schemes to analyse how private and public companies in Covid era can adapt and re-adapt their co-creating activities and knowledge sharing practices through new human-computer interactions to transform the knowledge generated into innovative insights that produce benefits for the entire community in a win-win logic.

Conceptualizing contemporary businesses as smart service systems allows to shed light on the transformative role of ICTs (Akaka et al., 2019) and information management (Lytras et al., 2021) in the regulation and coordination of interactions/relationships by revealing the mechanisms that foster efficient ways of addressing emerging challenges and disrupting events (Visvizi \& Lytras, 2019).

The exploration of how technology redefines human-computer interactions in smart cities- 
reinterpreted as smart service systems- permits to identify the new forms of interactions that can be developed and co-developed within the city for future smart environments (McKenna, 2020). In particular, new forms of evaluation of scholarly work, enhanced by the multiple touchpoints offered from new technologies and online teaching tools, can be introduced with the constant monitoring of users' opinion and data collection on community's evaluation.

As Figure 1 shows, the "smart" reinterpretation of service systems can be conceptualized through the following propositions (Grimaldi et al., 2020; Polese et al., 2020b):

1. the interactions between organizations and people (connection) are strengthened and intensified through the proliferation of multiple points of contact with users and technological channels (things);

2. the information exchanged is shared immediately and transparently (communication);

3. new technologies allow the continuous collection of data (data collection);

4. data is analyzed by applying analysis techniques (computation) to facilitate, through an integrated set of analytics, the transformation of information into knowledge (knowledge co-creation) and, therefore, into potential new value (value co-creation).

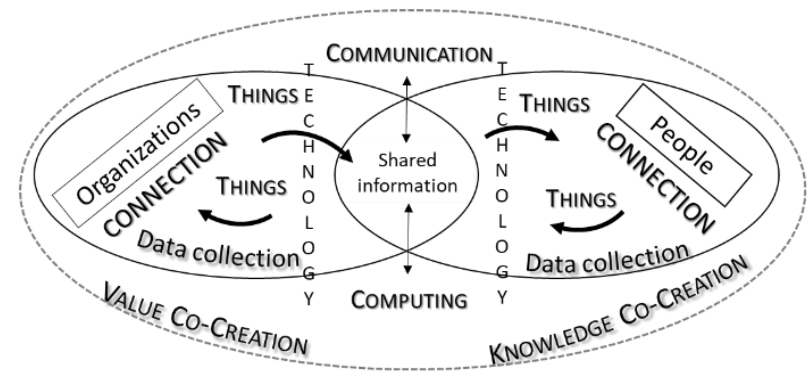

Figure 1. Value co-creation and knowledge co-creation in smart service systems

Smart service systems are understood as networks of actors who share and integrate resources tangible or intangible to carry out different activities (Beverungen et al. 2019), enhanced by the intensification of the contact points or technological channels (Maglio et al., 2009) which allow to collect and analyze data which, through the application of knowledge and renewed capabilities (knowledge co-creation), can be transformed into new value (value co-creation, Lim and Maglio, 2018). In line with extant research on strategic management (Teece and Pisano, 1997) and resourcebased view (RBV, Penrose, 1959; Barney, 1991), knowledge, skills and abilities can be intended as enabling factors for knowledge co-creation, whose activation can enable the emergence of successful value co-creation practices.

Therefore, observing the way in which actors interact and integrate resources and knowledge, through technology, allows at identifying the enabling factors for the birth of innovation (Malik et al., 2017; Acharya et al., 2018). As highlighted by previous studies on the topic, it is necessary to highlight how complex service systems are enhanced through the transformative role of new technologies and ICTs (Breidbach and Maglio, 2016; Akaka et al., 2019) to identify the main drivers that, dynamically combined, can release innovation (Frost and Lyons, 2017; Barile et al., 2017).

Specifically, the smart service system approach highlights the key role of data collection, information generation (computing), information sharing, and communication by suggesting that diffused value creation strategies may trigger the creation of new knowledge, new communication modes and practices, and eventually, innovation (Azoulay \& Jones, 2020; Reese et al., 2020; Malik \& Janowska, 2018). The potential novelties that can be co-created in smart service systems are depicted in Figure 2.

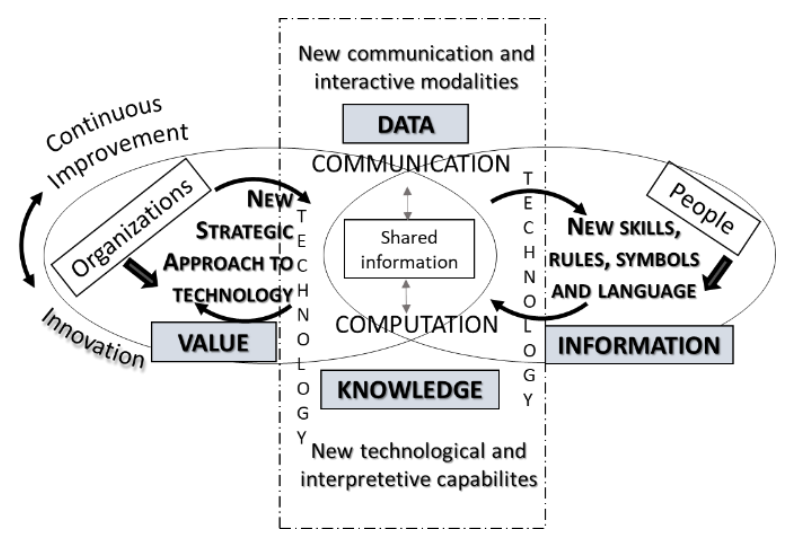

Figure 2. The emergence of innovation in smart service systems

People are intended as co-creating actors (Polese et al., 2018) that perform different activities through the combination of different interaction modalities, boosted by technological channels (from IT and ICTs systems to platforms and software). The active sharing of resources can facilitate the development of relational patterns that can foster the creation of common rules, new symbols and language and provide actors with the right interpretative schemes to accept technologies in daily lives and to extract relevant information from data.

Successful resources exchange can allow the renewal of actors' skills, knowledge and capabilities, that can be turned into value, insights and new value, therefore potential innovation. 
The novelties created enrich the system with renewed social roles, platforms, meanings, by providing actors with a new culture that institutionalizes and reproduce the new entities generated over time. The arrow in the figure represents the downward causation (Löbler, 2013; Lawson, 2013; Peters, 2014) effect of social reproduction that, after exchanges, renew the values generated over time through the externalization, formalization and institutionalization of knowledge that can lead to continuous improvement. The new values, knowledge, beliefs and meanings co-created are reinstitutionalized thanks to the emergence of new elements and properties that transform the "old" resources, that are different from the initial state and do not represent the outcome of the simple "sum" but have unexpected added value.

\section{Methodology}

To address the two research questions introduced above, the empirical research analyzes the sector of Higher education by collecting information on the impact of Covid-19 pandemic on learning and teaching tools and strategies from strategic documents and official statistics available on the Internet.

In particular, the IAU (International Association of Universities) Global Survey Report is employed to detect the main drivers that helped Italian universities (intended as smart service systems) survive the Pandemic through knowledge and value co-creation processes (RQ1). Then, starting from the identification of the main enablers of KCC and VCC, the new kind of novelties generated (RQ2) are categorized. The goal is to classify some drivers that can help contemporary universities overcome and manage crisis, environmental turbulence and technological and market evolutions.

The work adopts an exploratory qualitative approach based on a content analysis as inquiry (Losito, 1996), which allows at extracting from the texts (the unit of analysis) a smaller number of categories and to detect some focal points and key concepts (Krippendorff, 2004) relating to the different variables investigated through the application of semantic criteria established by the researchers.

Therefore, based on the key elements of the service systems and the sub-dimensions of innovation introduced in the previous paragraph, the content analysis sketch is divided according to the key variables and sub-variables shown in Table 1.

\begin{tabular}{|l|l|}
\hline Variables & Sub-dimensions \\
\hline
\end{tabular}

\begin{tabular}{|c|c|c|}
\hline $\begin{array}{l}\text { RQ1 } \\
\text { Enabling factors for } \\
\text { value co-creation and } \\
\text { knowledge co- } \\
\text { creation }\end{array}$ & $\begin{array}{l}\text { Enabling } \\
\text { dimensions } \\
\text { of smart } \\
\text { service } \\
\text { systems for } \\
\text { VCC }\end{array}$ & $\begin{array}{l}\text { People-Organizations } \\
\text { Technologies } \\
\text { Shared } \\
\text { information/communic } \\
\text { ation } \\
\text { Computation } \\
\text { Data collection }\end{array}$ \\
\hline $\begin{array}{l}\text { RQ2 } \\
\text { Key drivers that } \\
\text { foster the emergence } \\
\text { of different kinds of } \\
\text { novelties and } \\
\text { innovation }\end{array}$ & $\begin{array}{l}\text { Innovation } \\
\text { outcomes }\end{array}$ & $\begin{array}{l}\text { New attitude, mind-set, } \\
\text { culture } \\
\text { New interaction and } \\
\text { communication } \\
\text { modalities } \\
\text { New skills, rules } \\
\text { New technological and } \\
\text { interpretative } \\
\text { capabilities }\end{array}$ \\
\hline
\end{tabular}

Table 1 . The content analysis sketch

As regards the first research question, the main archetypal elements of the service systems (discussed in paragraph 2.1) that can act as enabling dimensions for the co-creation of value and knowledge are employed as macro-variables that can guide content analysis.

The outcomes of the co-creation of value and knowledge are investigated as antecedents of innovation (DR2) to detect the new values and knowledge produced within the Higher education system-

For the investigation of the different types of novelties generated, the sub-dimensions identified in the literature review (reported in paragraph 2.2), i.e. new attitude for organizations, new interaction modalities, new skills for people, new capabilities are considered as enabling factors for the emergence of innovation.

The texts have been explored through complex process of semantic interpretation. The variables investigated have been sub-divided into keywords useful to facilitate the search for topics and sub-topics within the text, which are then further specified in some sub-dimensions for each variable. The textual units are coded independently by three researchers based on a substruction process (Dulock and Holzemer 1991), which follows a synthesis approach that mediates between deduction (from general variables to specific keywords) and induction (from keywords to further specific sub-dimensions).

\section{Results}

The empirical research analzyes the IAU Global Survey on the impact of Covid-19 on universities and other higher education institutions. The report is part of a large set of research activities undertaken by the International Association of Universities (IAU), the leading global association of higher education institutions and organisations from around the world partner of UNESCO, to evaluate the consequences of pandemic on education sector. 


\subsection{The redefinition of Higher education as a service system during Covid era}

Higher education (HE) services in Covid-era can be interpreted as a series of technology-mediated interaction and experiential learning processes between students, teachers and the entire educational community, characterized by the enrichment of actor's knowledge, the sharing of meanings, languages and of a cohesive culture aimed at meeting system community goals (Erasmus and Albertyn, 2014; Lazarus, 2007).

Hence, due to the systems, interactional, technological cultural dimensions strictly involved in educational service, grounded on the exchange of knowledge, know-how, skills and capabilities through new "imposed" technology-enhanced learning tools, Higher Education can be reinterpreted as a smart service system.

The reinterpretation of $\mathrm{HE}$ as a smart service system implies the definition of education service as a complex process based on learning, teaching and evaluation activities performed through an integrated sets of technologies used by different co-creating actors with different goals and skills connected with multiple relationships based on the exchange of immaterial resources and knowledge.

Therefore, the analysis of IAU report, that helps the identification of the new interaction modalities and tools introduced after the advent of Pandemic and of universities' capabilities to tackle the emergency, can allow the investigation of: 1) the different enabling dimensions that can be used each level to foster value co-creation and knowledge co-creation through technology-enhanced learning (RQ1); 2) the emergence of innovation and social in $\mathrm{HE}$ as a result of the evolution "imposed" by the pandemic (RQ2).

\subsection{RQ1: Enabling dimensions of value and knowledge co-creation}

The majority of universities included in the sample reported that classroom teaching has been replaced completely by distance teaching and learning.

The IAU Global report identifies as series of challenges that can prevent the appropriate transition from face-to-face to distance teaching: 1) the access to technical infrastructure; 2) the competences and pedagogies for distance learning and the requirements of specific fields of study; 3 ) students engagement and motivation.

The right technological infrastructure to communicate with students and staff is a necessary but not sufficient condition for a clear and effective. Several institutions report that owning the right competencies in the use of technologies can be a key lever for transparent and timely information and communication flows.

Technical infrastructure and accessibility and online access are prerequisites for shifting to distance teaching and learning. The IAU Report reveals the potential gap and technological divide between developed and developing countries and between students who have access to the internet and students who do not, by making it difficult to provide every student with equal opportunities.

The report shows that a different pedagogy is required for distance teaching and learning to realize the unexpected shift from face-to-face to distance teaching and learning. The level of readiness or preparedness of teachers is the key lever for a continuing education and to guarantee the same level of quality compared to faceto-face education. Some institutions do not have a proper management structure to develop the teaching capabilities of staff in order to shift towards online learning easily and this can often result some attempts to imitate the face-to-face way of teaching by yet using distance mode.

If on the one hand the "forced" digitalization of teaching and learning offers the opportunity to adopt a more flexible service offering based on hybrid learning and on the combination of synchronous with asynchronous learning, most of the institutions that should tackle a sudden and unprepared shift to online teaching reveal that the enhancement of students' engagement and motivation are two key levers for the implementation of enhanced-teaching and learning.

The different enabling dimensions for knowledge and value co-creation identified in the analysis are shown in Figure 3.

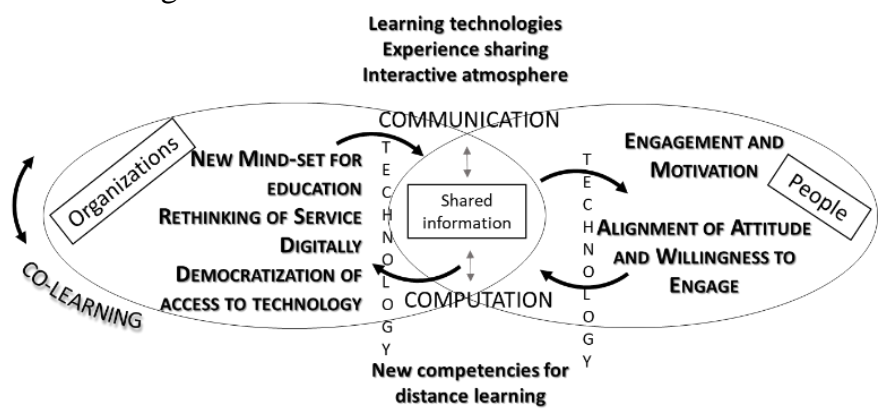

Figure 3. The identification of the key enablers of value co-creation and knowledge co-creation in higher education system in Covid-era

Hence, to help the transition to distance learning by preserving value and knowledge co-creation, Universities as organizations should change not only the methods of digital service provision but also the mindset for education, by pursuing democratic access to 
technology and rethinking the service/business digitally, as a new way of doing education and culture. Moreover, management should try to assess the ability-propensity of students and teachers in the use of technologies based on their level of digitization and their possible resistance in the use of telematic tools in work, study and of daily life.

Moreover, the people involved in the exchange (students, teachers, staff) should align their attitude, their background and willingness to engage.

Universities have the opportunity to employ smart technologies, platforms and mobile applications that enable human-computer interactions for synchronous online teaching and learning.

The learning technology tools for course interaction (such as Teams, Zoom) can support teacher and students in creating an interactive atmosphere in class. During the lesson, teachers can use various functions to enable the teacher-student interaction function and to let all students "raise their hands" or answer questions through different devices.

The integrated use of technology-enhanced learning tools can facilitate the sharing of experience, tacit and codified knowledge to obtain new knowledge, co-create new value and encourage co- learning processes. The use of IRS (interactive response systems platforms) can deliver learners' feedback to teachers and help gain real-time perceptions of students' understanding and facilitate the enhancement students' motivation. In this way, new ways of exchanging knowledge and creating new knowledge are generated. Students and digital natives can provide teachers with their experience, especially in the field of technology, due to their familiarity with the Internet and with ICTs.

Thus, the "forced" adoption of the new technological tools after the advent of Pandemic can permit the realization of co-learning. Education does not imply the unidirectional sharing of knowledge (from teachers to students) but empowers the enrichment of both students and teachers experience, know-how, tacit knowledge, culture and beliefs.

\subsection{RQ2: Innovation outcomes}

Many of the respondents of IAU Global Report understand the experience of working and teaching from distance as an important opportunity to learn and to propose more flexible learning possibilities, to explore hybrid learning and mix synchronous with asynchronous learning.

Hence, the unplanned and unprepared implementation of distance teaching and learning can lead to the improvement of both students' and teachers' skills who can learn to use new tools and systems to enable distance teaching and learning. Moreover, a shift in the mindset of people and in the attitude of university as an organization can be realized to open a new horizon of opportunities for teaching and learning.

As declared by several respondents of the survey, by exploring the potential of flexible learning, HE can benefit from an increase in innovation in the field of teaching pedagogies (e.g. in the general enhancement of skills) as well as in the delivery modalities of teaching and learning. Institutions may choose to invest further in technical infrastructures to enable the shift from management learning systems to cloud services, to digitalisation of administrative processes and of access to documents, resources and libraries. The enrichment of digital skills can enhance the access to lifelong learning opportunities.

Through learning management systems and platforms for online teaching, new communication and relational methods for technology-enhanced learning are created, based on timely information and on the possibility of being in contact 24 hours a day, through tools such as live chat, one-to-one and personalized assistance to students, etc.

According to most institutions included in the survey, Covid-19 had a positive impact on community engagement that has been boosted through medical care for affected people, medical advice and support, science communication initiatives and community actions.

Some respondents notice that the global emergency offers the opportunity to better prepare institutions to deal with similar crises in the future. Even if in the short term they are coping with the urgency of the situation, institutions can learn about crisis management by developing resilience and agility when responding to unforeseen challenges in the future.

The introduction of new teaching, learning and evaluation practices for scholars and students can develop constantly opportunities to change and pursue continuous improvement. The novelties emerged in the cultural system through distance learning are new methods for educational service provision, which can become stable practices over time and can be maintained even after the restarting of activities in the presence. For instance, online learning courses and exams can become a more integral part of study plans. Moreover, a new smart culture for training, learning, didactics and research that redefines languages and shared meanings between students, teachers and staff is introduced.

Data on teachers and student's performance are also stored in diagnostic reports by means of cloud systems to enhance self-systematic remedial learning. Starting from the collection of students' opinions and behaviours, teachers can make decisions based on statistical data and adjust teaching according to the information extracted. Moreover, data mining techniques are employed to discover and obtain 
knowledge from databases to support the analysis of student learning processes and the evaluation of the effectiveness and usability of online courses.

The different kinds of novelties generated in $\mathrm{HE}$ system through the new technological tools that enable value co-creation, knowledge co-creation and colearning are synthesized in Figure 4.

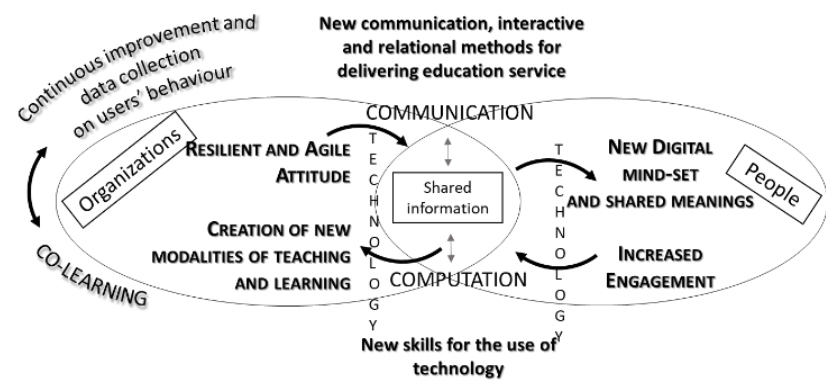

Figure 4. The different kinds of novelties generated in higher education system in Covid era

\section{Theoretical and managerial implications}

The study introduces a research agenda that encourages future research to explore how the emergence of innovation can be fostered in smart service systems by introducing: 1) a classification of the main antecedents of knowledge and value co-creation; 2) an investigation of the enabling factors that stimulate innovation are remodelled, through technologymediated interactions to pursue co-created innovation. Therefore, the transformative role of new technologies is explored to detect how the different combinations of resources, capabilities and use of technological tools can generate innovation through different relational models, by proposing the first steps to solve the gap arising from extant research on service innovation (Akaka et al., 2019). Therefore, the study enriches the research stream that explores the emergence of innovation in smart service systems, by categorizing the different drivers that promote innovation (Abbate et al., 2019).

The classification of innovation conceptualized in this study could lead managers to understand: 1) how smart technologies can produce different innovation outcomes based on the different types of stakeholders involved; 2) how different management strategies can produce different and new values; 3) how the new outcomes produced (new knowledge and value) can be constantly promoted and renewed over time to pursue continuous improvement (through constant adaptation and proactive re-adaptation of systems in complex contexts).

Furthermore, the study helps to clarify the relationship between the efficient use of ICTs technologies and platforms and the development of innovation (Barile et al., 2017). As a result, managers can acquire insights into the most appropriate combinations of technology and human interactions to manage the co-creation of value that can, in turn, allow for the harmonization of complex innovation processes. It is also possible to draw some suggestions how the interactions enabled by technology can enhance the dynamic integration of resources, through a constant process of adaptation and reconfiguration, thus helping to identify the main drivers for continuous improvement (Russo-Spena and Mele, 2012; Medina-Borja, 2015).

The work analyses the case of Higher Education by producing theoretical advancements on the classification of the different technological tools and drivers that can support the provision of educational services in the different moments of service provision and across the different resource integration and knowledge exchange involved in value co-creation and co-learning processes.

Education managers can understand: 1) how the use of different kind of technologies can help redefine the interaction modalities between and among students, teachers and community to challenge the global epidemic; 2) the key ecosystem's enablers for the development of different innovation opportunities through crisis resolution. Thus, the study detects, firstly, the main ecosystem's elements involved in Higher Education system to address the global emergency of Covid-19 and, secondly, how these elements can be harmonized to attain systems continuous re-adaptation that fosters social changes and transformation.

\section{Conclusion}

To clarify the opportunity and challenges deriving from Covid-19 management through technology, the findings of the study show how service systems can overcome the sanitary emergency by investing in value creation strategies that can give birth to the creation of new knowledge, rules and institutions (Gummesson, 2017a; Gervilla et al., 2020).

The framework advanced can help management, practitioners and scholars understand: 1) how technology, communication, information and resources integration are employed to challenge pandemic and perform online teaching and learning in $\mathrm{HE}$; 2) how systems adaptation can lead to the introduction of new modalities for teaching and learning that can change in the long- term the relationships among teachers, students, university management and community to determine transformation and to provide organizations with the ability to overcome crisis over time and, thus, to become resilient. 
The identification of the potential new interaction modalities and main strategies to challenge the pandemic can help scholars and practitioners identify the key drivers to overcome social and economic crisis. Moreover, the elaboration of a framework that analyses how technology can redefine humans' interactions and can foster social changes can address a gap in literature related to the absence of studies exploring the role of technologies in reframing community management and social innovation (Lytras and Visvizi, 2018).

The key limitation of the study is the narrowness of the textual data analyzed. Further studies can start from the dimensions identified in the framework to employ grounded theory according to a constructivist approach (Charmaz, 2002; Gummesson, 2017b), a technique usually employed in $\mathrm{HE}$, to perform observation and semi-structured interviews. What is more, additional research on the topic can start from the results proposed in the current study to apply the classification of the different drivers of VCC and KCC and of the different innovation outcomes to other service systems or to other contexts.

\section{References}

Abbate, T., Codini, A. P., \& Aquilani, B. (2019). Knowledge co-creation in open innovation digital platforms: processes, tools and services. Journal of Business \& Industrial Marketing, 34 (7), pp. 1434-1447.

Acharya, A., Singh, S. K., Pereira, V., \& Singh, P. (2018). Big data, knowledge co-creation and decision making in fashion industry. International Journal of Information Management, 42, 90-101.

Akaka, M. A., Koskela-Huotari, K., and Vargo, S. L. (2019), "Further Advancing Service Science with ServiceDominant Logic: Service Ecosystems, Institutions, and Their Implications for Innovation", In Handbook of Service Science, Volume II, pp. 641-659. Springer, Cham.

Azoulay, P., \& Jones, B. (2020), "Beat COVID-19 through innovation”, Science, 368 (6491), 553.

Barile, S., Ciasullo, M. V., Troisi, O., \& Sarno, D. (2017). The role of technology and institutions in tourism service ecosystems. The TQM Journal, 29 (6), pp. 811-833.

Barile, S., Polese, F. (2010). Smart service systems and viable service systems: Applying systems theory to service science. Service Science, 2(1-2), 21-40.

Barney, J. (1991). Firm resources and sustained competitive advantage. Journal of management, 17(1), 99-120.

Breidbach, C. F., Maglio, P. P. (2016). Technology-enabled value co-creation: An empirical analysis of actors, resources, and practices. Industrial Marketing Management, 56, 73-85.

Carrubbo L., Bruni R., Cavacece Y., Moretta Tartaglione A. (2015). Service system platforms to improve value cocreation: Insights for translational medicine. System Theory and Service Science: Integrating Three Perspectives in a New Service Agenda. Napoli: Giannini Editore.
Davis, M. M., Spohrer, J. C., Maglio, P. P. (2011). Guest editorial: How technology is changing the design and delivery of services. Operations Management Research, $4,1-5$.

Dulock, H. L., Holzemer, W. L. (1991). Substruction: Improving the linkage from theory to method. Nursing Science Quarterly, 4(2), 83-87.

Edvardsson, B., Gustafsson, A., Pinho, N., Beirão, G., Patrício, L., Fisk, R. P. (2014). Understanding value cocreation in complex services with many actors. Journal of Service Management. Vol. 25 No. 4, pp. 470-493.

Gervilla, M.J.Q., Díaz-Mendez M., \& Gummesson E. (2019), "Balanced centricity and triads: strategies to reach ecosystem equilibrium in the arts sector", Journal of Business \& Industrial Marketing, 35 (3), 447-456.

Grimaldi, M., Ciasullo, M. V., Troisi, O., \& Castellani, P. (2020). Data-Based Value Co-Creation in Smart Service Systems: A Reinterpretation of Customer Journey. International Journal of Business and Management, 15(4).

Gummesson, E. (2017a), "From relationship marketing to total relationship marketing and beyond", Journal of Services Marketing, 31(1), 16-19.

Gummesson, E. (2017b). Case theory in business and management: reinventing case study research. Sage.

Heinonen, K., \& Strandvik, T. (2020). Reframing service innovation: COVID-19 as a catalyst for imposed service innovation. Journal of Service Management.

Helkkula, A., Kowalkowski, C. and Tronvoll, B. (2018), "Archetypes of service innovation: implications for value cocreation", Journal of Service Research, 21(3), 284-301.

Hsieh, L., Chen, S.K., (2005), Incorporating voice of the consumer: does it really work? Industrial Management and Data Systems, 105 (6), 769-785.

https://www.iauaiu.net/IMG/pdf/iau_covid19_and_he_survey_report_fi nal_may_2020.pdf

Krippendorff, K. Measuring the reliability of qualitative text analysis data. Qual. Quant. 2004, 38(6), 787-800.

Lawson, T. (2013). Emergence And Social Causation. In R. Groff \& J. Greco (Eds.), Powers And Capacities In Philosophy: The New Aristotelianism, (pp. 285-307). London: Routledge Press.

Lim C., Maglio P.P., Kim K., Kim M., Kim K. (2016). Toward Smarter Service Systems through Service-oriented Data Analytics. Proceedings of 2016 I.E. International Conference on Industrial Informatics, 1-6. https://doi.org/10.1109/INDIN.2016.7819295

Lim C., Maglio P.P., Kim K., Kim M., Kim K. (2016). Toward Smarter Service Systems through Service-oriented Data Analytics. Proceedings of 2016 I.E. International Conference on Industrial Informatics, 1-6. https://doi.org/10.1109/INDIN.2016.7819295

Lim C., Maglio P.P., Kim K., Kim M., Kim K. (2016). Toward Smarter Service Systems through Service-oriented Data Analytics. Proceedings of 2016 I.E. International Conference on Industrial Informatics, 1-6. https://doi.org/10.1109/INDIN.2016.7819295

Lim, C., Maglio, P. P. (2019). Clarifying the Concept of Smart Service System. In Handbook of Service Science, Volume II (pp. 349-376). Springer, Cham. 
Löbler, H. (2013) Service-Dominant Networks: An Evolution From The Service-Dominant Logic Perspective, Journal of service management, 24 (4), 255-282.

Losito, G. (1996). L'analisi del contenuto nella ricerca sociale (Vol. 1). FrancoAngeli.

Lusch, R.F., Nambisan, S. (2015), "Service Innovation: A Service-Dominant Logic Perspective", MIS Quarterly, Vol. 39 No. 1, pp. 155-175.

Lytras, M. D., \& Visvizi, A. (2018). Who uses smart city services and what to make of it: Toward interdisciplinary smart cities research. Sustainability, 10(6), 1998.

Lytras, M. D., Visvizi, A., Chopdar, P. K., Sarirete, A., \& Alhalabi, W. (2021). Information Management in Smart Cities: Turning end users' views into multi-item scale development, validation, and policy-making recommendations. International Journal of Information Management, 56, 102146.

Maglio, P. P., Kieliszewski, C. A., Spohrer, J. C., Lyons, K., Patrício, L., \& Sawatani, Y. (Eds.). (2019). Handbook of Service Science, Volume II. Springer International Publishing.

Maglio, P. P., Spohrer, J. (2008). Fundamentals of service science. Journal of the academy of marketing science, 36(1), 18-20.

Malik, A., Pereira, V., \& Budhwar, P. (2017). Value creation and capture through human resource management practices: Gazing through the business model lens. Organizational Dynamics.

Malik, R., \& Janowska, A. A. (2018). Megatrends and their use in economic analyses of contemporary challenges in the world economy. Prace Naukowe Uniwersytetu Ekonomicznego we Wroctawiu, (523), 209-220.

Marinoni, G., Van't Land, H., \& Jensen, T. (2020). The impact of Covid-19 on higher education around the world. IAU Global Survey Report.

Medina-Borja A. (2015) Editorial Column-Smart Things as Service Providers: A Call for Convergence of Disciplines to Build a Research Agenda for the Service Systems of the Future. Service Science 7(1):ii-v. https://doi.org/10.1287/ serv.2014.0090

$\mathrm{Ng}$ I. (2015). The Internet of Everything and the Future of Service. Speech, 2015 Frontiers in Service Conference in San Jose, CA. Available at: http://hubofallthings.com/hat-in-the-usa/.

Penrose, E. T. (1959). The Theory of the Growth of the Firm. New York: John Wiley

Peters, L. D. (2016). Heteropathic versus homopathic resource integration and value co-creation in service ecosystems. Journal of Business Research, 69(8), 29993007.

Polese, F., Botti, A., Grimaldi, M., Monda, A., Vesci, M. (2018), "Social innovation in smart tourism ecosystems: How technology and institutions shape sustainable value co-creation", Sustainability, 10(1), 140.

Polese, F., Sarno, D., \& Vargo, S. L. (2020a), "The Role of Emergence in Service Systems", In Proceedings of the 53rd Hawaii International Conference on System Sciences.

Polese, F., Troisi, O., Grimaldi, M., \& Sirianni, C. (2020b). Conceptualizing social change, between value cocreation and ecosystems innovation. Marketing as a social Science: Festschrift für Universitätsprofessor Dr. Dr. hc Helge Löbler, 203

Kabadayi, S., O'Connor, G.E. and Tuzovic, S. (2020), "Viewpoint: the impact of coronavirus on service ecosystems as service mega-disruptions", Journal of Services Marketing, doi: 10.1108/JSM-03-2020-0090.

Prahalad, C.K., Ramaswamy, V., (2003). The new frontier of experience innovation. MIT Sloan Management Review, 44 (4), 12-18

Reese, S. (2020). Learning organizations and value creation. The Learning Organization, 27(4), 379-382

Romero, D., Molina, A. (2011). Collaborative networked organisations and customer communities: value cocreation and co-innovation in the networking era. Production Planning \& Control, 22(5-6), 447-472.

Russo-Spena, T., \& Mele, C. (2012). "Five Co-s" in innovating: a practice-based view. Journal of Service Management, 2(4), 527-553.

Spohrer, J. C., Demirkan, H. (2015). Introduction to the smart service systems: Analytics, cognition, and innovation minitrack. In 2015 48th Hawaii International Conference on System Sciences (pp. 1442-1442). IEEE.

Spohrer, J., Maglio, P. P., Bailey, J., Gruhl, D. (2007), "Steps Toward A Science Of Service Systems", Computer, Vol. 40, No. 1.

Spohrer, J., Vargo, S. L., Caswell, N., Maglio, P. P. (2008), "The service system is the basic abstraction of service science", in Hawaii International Conference on System Sciences, Proceedings of the 41st Annual, pp. 104-104

Storbacka, K., Brodie, R. J., Böhmann, T., Maglio, P. P., Nenonen, S. (2016). Actor engagement as a microfoundation for value co-creation. Journal of Business Research, 69(8), 3008-3017.

Su, C.-Y., Lin, B.-W., Chen, C.J. (2016). Knowledge cocreation across national boundaries: Trends and firms' strategies. Knowledge Management Research and Practice, 14(4), 457-469.

Teece, D. J., Pisano, G., \& Shuen, A. (1997). Dynamic capabilities and strategic management. Strategic management journal, 18(7), 509-533.

Troisi, O., Visvizi, A. and Grimaldi, M. (2021), "The different shades of innovation emergence in smart service systems: the case of Italian cluster for aerospace technology", Journal of Business \& Industrial Marketing, Vol. aheadof-print No. ahead-of-print

Vargo, S. L., Wieland, H., Akaka, M. A. (2015). Innovation through institutionalization: A service ecosystems perspective. Industrial Marketing Management, 44, 6372.

Visvizi, A., \& Lytras, M. (Eds.). (2019). Smart Cities: Issues and Challenges: Mapping Political, Social and Economic Risks and Threats, Elsevier.

Visvizi, A., Lytras, M., Damiani, E. \& Hassan, M. (2018). Policy making for smart cities: Innovation and social inclusive economic growth for sustainability. Journal of Science and Technology Policy Management. 9(2), 126133. https://doi.org/10.1108/JSTPM-07-2018-079.

Von Hippel, E., (2005). Democratizing innovation: the evolving phenomena of user innovation. Journal für Betriebswirtschaft, 55, 63-7 